\title{
Activation of Cement in a Jet Mill
}

\author{
S. Titov ${ }^{(凶)}$ and A. Kazakov \\ Federal State Budgetary Educational Institution, Russian University of Transport \\ (MIIT), Moscow, Russia \\ titovs3094@yandex.ru
}

\begin{abstract}
Mechanical treatment of cement in a jet mill leads to an increase in the strength of cement-sand stone in compression and during bending. The effect of increased activity is achieved by changing the shape of cement particles from angular to rounded.
\end{abstract}

Keywords: Cement $\cdot$ Jet mill $\cdot$ Cement activity $\cdot$ Compressive strength $\cdot$ Bending strength $\cdot$ Particle shape factor

\section{Introduction}

Activation is a set of measures aimed at increasing the activity of cement by exposing it to various mechanical methods. As a result of such exposure, physical and chemical processes of different nature occur in the raw materials, leading to a change in the characteristics of the final product (Kuznetsova and Sulimenko 1985). As a rule, during mechanical activation, cement is crushed with an increase in its specific surface.

In a jet mill, activation occurs due to processing of cement in turbulent swirling flows (Korchakov 1986), leading not only to grinding, but also to transformation of the shape of particles from angular to rounded.

\section{Methods and Approaches}

The analysis of the shape of cement particles modified in a jet mill was performed using the proposed shape criterion:

$$
k_{i}=\left(S / P^{2}\right)^{i}
$$

where $\mathrm{S}$ - area of the particle in the plane of its cross section, $\mathrm{P}$ - length of the perimeter in the cross section of the particle; $i-$ order of the criterion $(i=1 / n . ., 1, \ldots, n$, where $\mathrm{n}$ - counting numerals).

To determine the degree of influence of the particle shape on the properties of cement systems, standard samples were tested and the results obtained were processed using mathematical statistics methods. 


\section{Results and Discussion}

It was found that processing in a jet type mill leads to an increase in dispersity of cement from $5 \%$ to $0.8-1.2 \%$ on sieve No. 008 with a non-significant change in normal density of the cement paste.

Increasing the fineness of cement grinding causes, as a rule, an increase in mixing water consumption to obtain a mixture of equal workability. But the experiment showed the opposite - the water-cement ratio of the solution prepared on cement, processed in a jet mill, not only did not increase, but also decreased. This is due to the change in the shape of cement particles from angular to rounded, which was statistically justified using the proposed shape criterion $k_{i}(1)$.

The results of the tests showed an increase in strength of the samples based on portland cement processed in a jet mill for compression by $38-68 \%$ and by bending by $12-25 \%$ compared to non-activated cement.

\section{Conclusions}

The increase in compressive strength and bending of the samples based on cement processed in a jet mill is explained by the change in the shape of its particles from angular to rounded, which is associated with the characteristics of the vortex activation method.

Acknowledgements. The authors express their gratitude to the research supervisor, D.Sc. (Eng), prof. Kondrashchenko V.I.

\section{References}

Korchakov VG (1986) Aerodynamics of flows in jet mills when grinding silicate materials, Ph.D. (Eng) thesis, Kharkov, $168 \mathrm{p}$

Kuznetsova TV, Sulimenko LM (1985) Mechanical activation of portland cement raw mixtures. Cement, no 4, pp 20-21

Open Access This chapter is licensed under the terms of the Creative Commons Attribution 4.0 International License (http://creativecommons.org/licenses/by/4.0/), which permits use, sharing, adaptation, distribution and reproduction in any medium or format, as long as you give appropriate credit to the original author(s) and the source, provide a link to the Creative Commons license and indicate if changes were made.

The images or other third party material in this chapter are included in the chapter's Creative Commons license, unless indicated otherwise in a credit line to the material. If material is not included in the chapter's Creative Commons license and your intended use is not permitted by statutory regulation or exceeds the permitted use, you will need to obtain permission directly from the copyright holder.

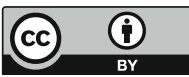

